\title{
PRECISE ASSESSMENT OF PERFORMANCE OF INDUCTION MOTOR UNDER SUPPLY IMBALANCE THROUGH IMPEDANCE UNBALANCE FACTOR
}

\author{
Shashi Bhushan Singh — Asheesh Kumar Singh*
}

\begin{abstract}
This paper presents precise assessment of steady-state performance of induction motor (IM) operating under voltage unbalance. The variation of two voltage unbalance factors viz. complex voltage unbalance factor (CVUF) and impedance unbalance factor (IUF) with positive sequence voltage component, reveals that degree and manner of unbalance in supply voltage is exactly reflected in CVUF and IUF, respectively. On this basis, it is shown that for the precise assessment of IM performance, knowledge of both, manner (IUF) and degree (CVUF) of unbalance is important. Further, effect of angle of unbalance, on the performance of the IM and voltage pattern is analyzed. Results depict high sensitivity of derating factor and peak copper losses to this angle. Thus, it should be included along with unbalance factors for the precise and complete performance assessment of IM.
\end{abstract}

K e y w or d s: complex voltage unbalance factor, derating factor, impedance unbalance factor, induction motor, voltage pattern

\section{INTRODUCTION}

With the development of the power electronics technology, increase of different types of nonlinear loads, rapid growth in electric railways in some developing country, and uneven distribution of load, power quality (PQ) problem has become a major concern for both electric utilities and customers. Due to poor PQ, billions of dollars are being wasted every year. Voltage unbalance exist due to the incomplete transposition of transmission line, unbalance load, open delta transformer connection, uneven distribution of single phase load [1-6] is now considered as the one of the most important aspect of $\mathrm{PQ}$ disturbances. Based on ANSI report presented in [3], the $32 \%$ of the USA electrical distribution system have degree of voltage unbalance lies between 1 and $3 \%$ whereas $2 \%$ of distribution system have degree of unbalance more than $3 \%$. According to IEC recommendation the maximum voltage unbalance of supply system should be not more than $2 \%$ $[3,4]$ where as NEMA MG1-1993 "Motor and Generator" recommends that for voltage unbalance greater than $1 \%$, Induction motor (IM) should be derated [3]. The voltage unbalance in three phase system is practically impossible to be obviated due to their inherent causes and further this problem is aggravated by the fact that the presence of small unbalance in three phase system will causes the unproportional unbalance in the line current [5]. So there is a need for researchers to pay special attention on the topic of voltage unbalance.

Voltage unbalance has very considerable effect on three phase IM, including torque pulsation, overheating, derating, pulsation in peak current, inefficiency etc. The life time estimation of IM, maintenance of the machine etc are directly related to the degree and manner of unbalance to which machines are to be subjected [5] and hence study of IM under unbalance condition of supply voltage is one of the most important topics in research. A lot of researches have been reported in the literatures regarding adverse effect of voltage unbalance on IM. The effects of voltage unbalance on winding temperature, efficiency, power factor, total loss, derating factor of IM etc are well documented in [5-11]. In [5], eight conditions of voltage unbalances are considered and effects of unbalance on the performance of IM are analyzed with same voltage unbalance factor (VUF). It is shown that for the same value of VUF, the efficiency and power factor of the machine depends on the manner of unbalance. This paper concludes that it is essential to consider positive sequence voltage for accurate assessment of voltage unbalance. In [6], discussion about the efficiency of IM under unbalance condition has been presented while [7], discusses about the derating factor, winding temperature and thermal loss of life on fed IM operating with over and under voltage along with differences in definition of voltage unbalance. The effect of voltage unbalance winding temperature of IM has been discussed in [8-10]. To analyze the effect of voltage unbalance in phase frame, a new method has been developed in [11]. This method reduces the complexity arises in transforming phase to sequence component and vice versa and also investigates the increases in losses under unbalance supply voltage condition. In all of these aforementioned studies [5-11], either the percent voltage unbalance (PVU) defined by NEMA [12], or VUF defined by IEC [13] have been consider for the degree of unbalance. The PVU is ratio of maximum deviation of line voltage from average voltage, to the average of three line

* EED, MNNIT, Allahabad, India 211004, shashidce@gmail.com, asheesh@mnnit.ac.in 


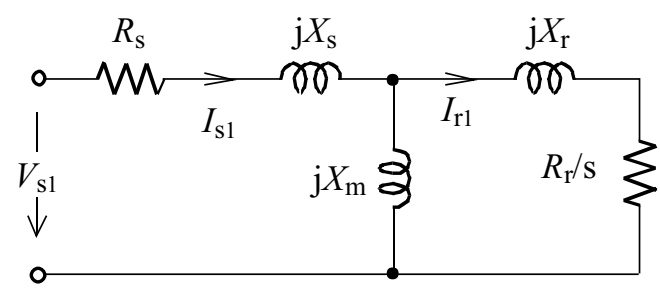

(a)

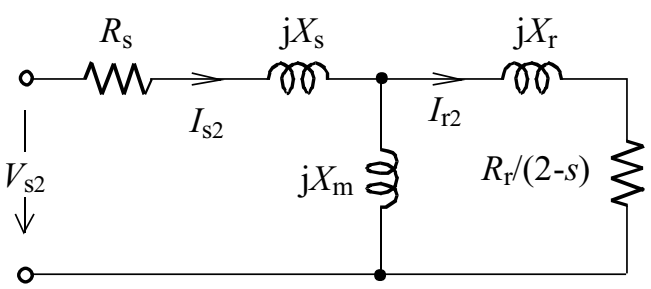

(b)

Fig. 1. Single phase equivalent circuit of the motor: (a) - positive sequence circuit, (b) - negative sequence circuit

voltage where as VUF is the ratio of absolute value of negative to positive sequence voltage [5], [12-14]. Phase angle of unbalance has been ignored in these researches while phase angle play vital role in determination of the pattern of voltage, calculation of peak loss, phase loss, derating factor, maximum allowable slip for worst and favourable condition. Thus, the effect of supply voltage unbalance on steady state performance of IM becomes far from the real analysis in these researches. Further contributions toward steady state performance analysis of IM under unbalance supply voltage condition were made in [1], [15-17]. These literatures modified the IEC definition of voltage unbalance by including the phase angle unbalance factor in evaluating the effect of unbalance on the steady state performance of the IM. All of these literature declared that the complete definition of voltage unbalance is not VUF but CVUF. In [15], special emphasis is placed on the effect of the angle of CVUF on the performance of IM and most favourable and worst case for derating factor and maximum allowable slips are discussed whereas in [16] normalized negative sequence component is used in substitution to VUF to judge the effect of unbalance. Different definitions of the voltage unbalance are analyzed in [17] and by using these definitions the variation of the unbalance voltage in 3 -D locus are plotted to reduce the range of the variation of terminal voltages. A new coefficient of unbalance is defined in [1] and it is shown that coefficient of unbalance along with CVUF can be applied for precise analysis of the performance of IM under unbalance supply voltage condition; further stress is given on the angle of CVUF to determine the accurate value of derating factor. In fact, IEC definition of voltage unbalance is not sufficient to assess precisely the effect of supply voltage unbalance on the steady state performance of the IM, as it describes only the magnitude, whereas heating of the motor and pattern of the voltage is also affected by the angle of positive and negative sequence voltage components. Thus to make more precise and complete assessment of the performance of IM, angle of unbalance should be included. Some of the aforementioned studies discussed above, consider both the magnitude and angle of unbalance factor and emphasized that the magnitude and angle of unbalance factor are sufficient for complete and precise assessment of the performance of the IM in the condition of unbalance.

This paper shows that, only magnitude and angle of unbalance factor, ie CVUF is not sufficient to assess the performance of the IM precisely, there is also need to define the manner of unbalance or the conditions of the unbalance. It is shown that for a fixed value CVUF, the accurate calculation of efficiency, power factor, losses etc is not possible, exact voltage unbalance condition is also needed for it. Thus for the complete and precise assessment of the influence of unbalance voltage, one more factor should be included in addition to CVUF. In this paper magnitude of IUF, with CVUF are taken into consideration for the precise assessment of influence of unbalance. Further special emphasis is placed on the effect of angle of unbalance on derating factor, peak copper loss and pattern of the voltage. The relation between IUF \& positive sequence component voltage has been also discussed. Discussion result in, magnitude of IUF is the measurement of the manner of unbalance where as magnitude of CVUF is the measurement of the degree of unbalance. The symmetrical component theory with MATLAB simulation is used to investigate the performance analysis of IM.

\section{SYMMETRICAL COMPONENT ANALYSIS OF IM AND PATTERN OF UNBALANCE VOLTAGE}

Disturbance of positive sequence voltage due to zero and negative sequence voltage can be considered as voltage unbalance and under- or over-voltage is the consequence of it. Since the IM are connected either in star without neutral or in delta so the zero sequence component is absent and hence negative sequence component becomes the primary cause of voltage unbalance [15]. Hence it can be said that voltage unbalance is a superposition of negative sequence voltage over positive sequence voltage. The result of superposition decides the condition of over and under voltage. If positive sequence component of voltage disturbed in such a way that it magnitude become less than one (in pu) then this event is under-voltage whereas for more than one (in pu), the condition is over -voltage [18].

\subsection{Symmetrical Component Analysis}

Positive and negative sequence equivalent circuit of IM under the unbalance supply voltage condition is shown in Fig. 1. In the figure $R_{s}$ and $X_{s}$ are the stator resistance and reactance, $R_{r}$ and $X_{r}$ stator referred rotor resistance and reactance, $X_{m}$ the magnetizing reactance, $I_{s 1}$ and 
$I_{r 1}$ the stator and rotor positive sequence current, $I_{s 2}$ and $I_{r 2}$ the stator and rotor negative sequence voltage and $s$ is the slip of the IM respectively.

Let $V_{s a}, V_{s b}$, and $V_{s c}$ be a set of line to neutral voltages of stator windings and $V_{s 0}, V_{s 1}$ and $V_{s 2}$ are the zero, positive and negative sequence component voltage respectively. The relation between unbalance phasor and sequence component is given by (1) and $(2),[1,15]$

$$
\begin{aligned}
& V_{s 1}=\frac{V_{s a}+a V_{s b}+a^{2} V_{s c}}{3}=V_{s 1} \angle \beta, \\
& V_{s 2}=\frac{V_{s a}+a^{2} V_{s b}+a V_{s c}}{3}=V_{s 2} \angle \beta+\theta_{v} .
\end{aligned}
$$

where ' $a$ ' is the Fortescue operator equal to $1.0 \exp (j 2 \pi / 3)[15], \beta$ and $\beta+\theta_{v}$ are the angle of positive and negative sequence voltage component respectively.

The input sequence impedances for the positive and negative sequence circuit are given by (3) and (4) respectively

$$
\begin{aligned}
& Z_{s 1}=\left(R_{s}+j X_{s}\right)+\frac{\left(\frac{R_{r}}{s}+j X_{r}\right) j X_{m}}{\frac{R_{r}}{s}+j\left(X_{m}+X_{r}\right)}=Z_{s 1} \angle \varphi_{p}, \\
& Z_{s 2}=\left(R_{s}+j X_{s}\right)+\frac{\left(\frac{R_{r}}{2-s}+j X_{r}\right) j X_{m}}{\frac{R_{r}}{2-s}+j\left(X_{m}+X_{r}\right)}=Z_{s 2} \angle \varphi_{n}
\end{aligned}
$$

where $\varphi_{p}$ and $\varphi_{n}$ are the angle of positive and negative sequence input impedances respectively.

Symmetrical component of the stator current can be found with help of (1)-(4) and given by

$$
\begin{aligned}
& I_{s 1}=\frac{V_{s 1}}{Z_{s 1}}=I_{s 1} \angle \beta-\varphi_{p}, \\
& I_{s 2}=\frac{V_{s 2}}{Z_{s 2}}=I_{s 2} \angle \beta+\theta_{v}-\phi_{n} .
\end{aligned}
$$

With the help of symmetrical component analysis $[1,15]$, unbalance phase current of the stator winding can be given by

$$
\begin{aligned}
& I_{s a}=I_{s 1}+I_{s 2}, \\
& I_{s b}=a^{2} I_{s 1}+a I_{s 2}, \\
& I_{s c}=a I_{s 1}+a^{2} I_{s 2} .
\end{aligned}
$$

The ratio of $V_{s 2}$ to $V_{s 1}$ in phasor form is termed as CVUF [1,4,15-17] and is given as

$$
\mathrm{CVUF}=\frac{V_{s 2}}{V_{s 1}}=k_{v} \angle \theta_{v}
$$

where $k_{v}$ and $\theta_{v}$ are the magnitude and angle of CVUF for phase voltage respectively. The angle, $\theta_{v}$ indicates the angle by which $V_{s 2}$ leads the $V_{s 1}$, and it is very important parameter to decide the pattern of voltage under different condition of unbalance whereas $k_{v}$ is the measurement of the intensity of severity. Normally the $V_{s 1}$ is very close to unity in per unit value and correspondingly $k_{v}$ will be very close to $V_{s 2}$. In other we can say that $k_{v}$ is the measurement of $V_{s 2}$. For this reason the IEC definition of voltage unbalance also referred as true value compared to NEMA definition [7]. However the NEMA definition for the measurement of degree of unbalance is convenient to field measurement because it does not require the phase of the unbalance voltages but for physical interpretation of the cause of voltage unbalance IEC definition is very useful. To measure the level of degree of unbalance of stator current some literature also discussed complex current unbalance factor (CCUF) $[15,19]$. CCUF for stator is given by

$$
\mathrm{CCUF}=\frac{I_{s 2}}{I_{s 1}}=k_{c s} \angle \theta_{c s}
$$

where $\theta_{c s}$ and $k_{c s}$ are the angle and magnitude of CCUF for stator. The relation between $k_{c s} \& k_{v}$, and $\theta_{c s} \& \theta_{v}$ can be easily deduced with help of (5) and (6) and given as

$$
\begin{aligned}
k_{c s} & =\frac{k_{v}}{k_{z}} \\
\theta_{c s} & =\theta_{v}+\phi_{p}-\phi_{n}
\end{aligned}
$$

where $k_{z}$ is the ratio of input negative sequence $\left(Z_{s 2}\right)$ to positive sequence impedance $\left(Z_{s 1}\right)$ and considered as the sensitivity of $k_{v}$ to $k_{c s}$.

The value of the stator phase current as a function of $k_{c s}$ and $\theta_{c s}$ can be easily deduced with the help of (7)-(9) and given as

$$
\begin{aligned}
& \left|I_{s a}\right|=\left|I_{s 1}\right| \sqrt{1+k_{c s}^{2}+2 k_{c s} \cos \left(\theta_{c s}\right)}, \\
& \left|I_{s b}\right|=\left|I_{s 1}\right| \sqrt{1+k_{c s}^{2}+2 k_{c s} \cos \left(\theta_{c s}-\frac{2 \pi}{3}\right)}, \\
& \left|I_{s c}\right|=\left|I_{s 1}\right| \sqrt{1+k_{c s}^{2}+2 k_{c s} \cos \left(\theta_{c s}+\frac{2 \pi}{3}\right)} .
\end{aligned}
$$

Similarly rotor phase current can be calculated with the help of Fig. 1 and symmetrical component analysis in term of magnitude $\left(k_{c r}\right)$ and argument $\left(\theta_{c r}\right)$ of rotor CCUF and given as

$$
\begin{aligned}
& \left|I_{r a}\right|=\left|I_{r 1}\right| \sqrt{1+k_{c r}^{2}+2 k_{c r} \cos \left(\theta_{c r}\right)}, \\
& \left|I_{r b}\right|=\left|I_{r 1}\right| \sqrt{1+k_{c r}^{2}+2 k_{c r} \cos \left(\theta_{c r}-\frac{2 \pi}{3}\right)}, \\
& \left|I_{r b}\right|=\left|I_{r 1}\right| \sqrt{1+k_{c r}^{2}+2 k_{c r} \cos \left(\theta_{c r}+\frac{2 \pi}{3}\right)}
\end{aligned}
$$

where $k_{c r}$ and $\theta_{c r}$ are given as

$$
\begin{aligned}
& k_{c r}=\left|\frac{I_{r 2}}{I_{r 1}}\right|, \\
& \theta_{c r}=\theta_{v}+\varphi_{p}-\varphi_{n}+\theta_{2}-\theta_{1}
\end{aligned}
$$




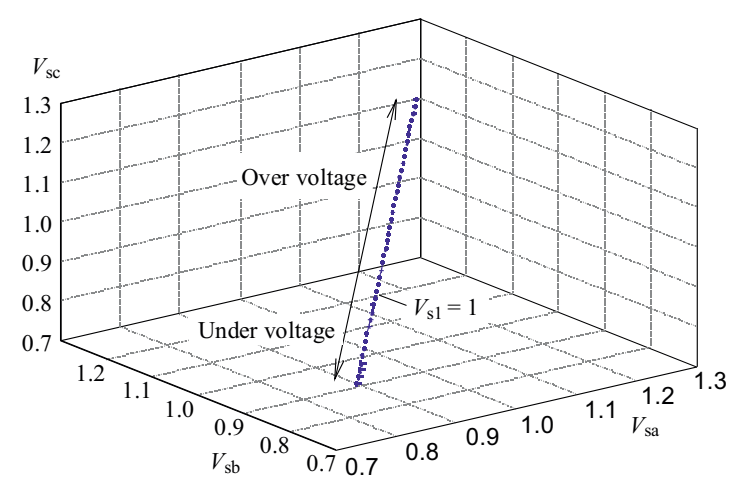

Fig. 2. The 3-D locus of line voltages for different value of $V_{s 1}$ and $\theta_{v}=45^{\circ}, k_{v}=3 \%$

where $\theta_{1}$ and $\theta_{2}$ are the argument of $X_{1}$ and $X_{2}$ given as

$$
\begin{aligned}
& X_{1}=\frac{j X_{m}}{\frac{R_{r}}{s}+j\left(X_{m}+X_{r}\right)}, \\
& X_{2}=\frac{j X_{m}}{\frac{R_{r}}{2-s}+j\left(X_{m}+X_{r}\right)} .
\end{aligned}
$$

Stator copper loss $\left(P_{\text {sloss }}\right)$ and rotor copper loss $\left(P_{\text {rloss }}\right)$, output power $\left(P_{\text {out }}\right)$, output torque $\left(T_{\text {out }}\right)$, complex input power $\left(S_{i}\right)$, input power $\left(P_{\text {in }}\right)$, reactive input power $\left(Q_{i}\right)$, efficiency $(\eta)$, and power factor $(p f)$ in term CCUF, s, and sequence component can be easily obtained with help of above equations and given as

$$
\begin{aligned}
P_{\text {sloss }} & =3 I_{s 1}^{2} R_{s}\left(1+k_{c s}^{2}\right), \\
P_{\text {rloss }} & =3 I_{r 1}^{2} R_{s}\left(1+k_{c r}^{2}\right), \\
P_{\text {out }} & =3 I_{r 1}^{2} R_{r}\left[\left(\frac{1}{s}-1\right)+k_{c r}^{2}\left(\frac{1}{2-s}-1\right)\right], \\
T_{\text {out }} & =\frac{3 I_{r 1}^{2} R_{r}}{\omega_{s}}\left[\frac{1}{s}-\frac{k_{c r}^{2}}{2-s}\right], \\
S_{i} & =\left(V_{s 1} I_{s 1}^{*}+V_{s 2} I_{s 2}^{*}\right), \\
P_{i} & =\operatorname{Re}\left(S_{i}\right), \\
Q_{i} & =\operatorname{Im}\left(S_{i}\right), \\
\% \eta & =\frac{P_{\text {out }}}{P_{i}} \times 100, \\
p f & =\cos \left(\tan ^{-1} \frac{Q_{i}}{P_{i}}\right) .
\end{aligned}
$$

\subsection{Pattern of Voltage under the Condition of Supply Voltage Unbalance}

With the help of (1) and (2), and considering $V_{s 1}$ as reference, we can easily derived the relation between three phase voltage and given by

$$
V_{s a}=A V_{s b}+B V_{s c}
$$

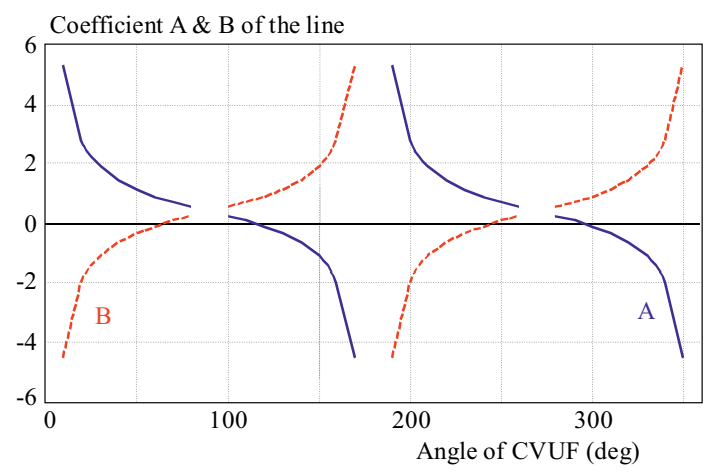

Fig. 3. Variation of $A$ and $B$ with angle of unbalance

where $A$ and $B$ are the coefficient of phase voltage given by

$$
\begin{aligned}
& A=\frac{\tan \theta_{\nu}+\sqrt{3}}{2 \tan \theta_{\nu}}, \\
& B=\frac{\tan \theta_{\nu}-\sqrt{3}}{2 \tan \theta_{\nu}} .
\end{aligned}
$$

The locus of three phase voltages in 3-D plane for fixed value of $k_{v}$ and $\theta_{v}$ is shown in Fig. 2 .

From Fig. 2, it can be observed that there are number of unbalance condition for fixed value of $k_{v}, \theta_{v}$. As the value of $k_{z}$ changes from $15 \%$ to $30 \%$, the condition of unbalance or the pattern of voltage changes from under voltage to overvoltage. It is also important to note that there are number of unbalance condition included in under- and over- voltage which are termed as mixed under- and over- voltage, discussed in [20]. Thus we can conclude at this stage that only the $k_{v}, \theta_{v}$ are not enough for the precise assessment of the performance of the IM in unbalanced supply voltage condition.

Figure 3 shows the variation of the coefficient $A$ and $B$. It can be observed that the angle $\theta_{v}$ plays very important role to find out the slope of straight line obtained in 3-D plane. As the value of $\theta_{v}$ changes the slope of the line will change. Hence, the angle $\theta_{v}$ is also very important to determine the pattern of voltage, especially for the calculation of the derating factor and peak copper loss of the motor. The role of $\theta_{v}$ in the assessment of the performance of motor is discussed in next section.

\section{STEADY STATE ANALYSIS OF THREE PHASE IM UNDER SUPPLY VOLTAGE UNBALANCE}

The ill effects of the unbalance voltage on the IM stem from the fact that the unbalance voltage breaks down in positive and negative sequence components of voltage. The negative sequence component of voltage produces an air gap flux rotating against the rotation of rotor and thus 


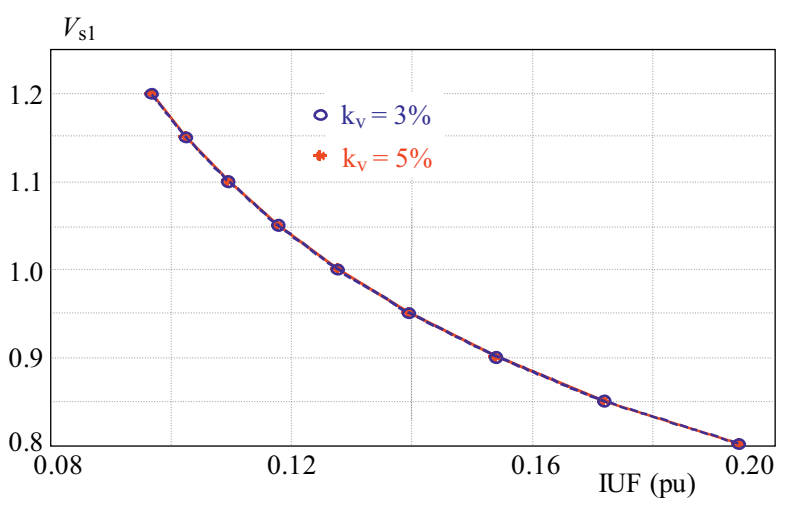

Fig. 4. Variation of positive sequence component of voltage (pu) with $k_{z}(\mathrm{pu})$

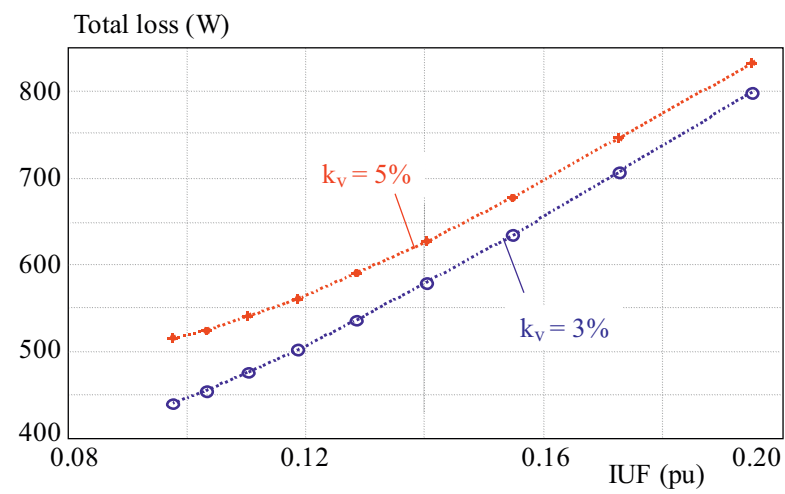

Fig. 6. The variation of total loss of IM with $k_{z}(\mathrm{pu})$

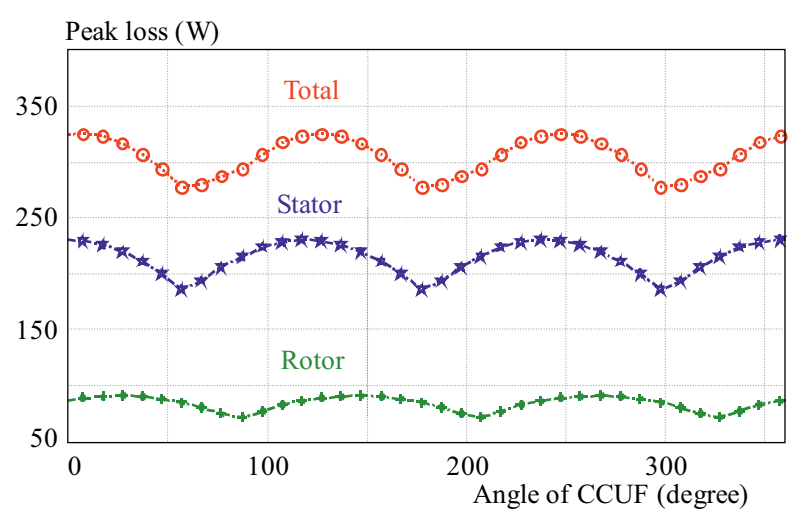

Fig. 8. The variation of peak stator, rotor and total copper loss of IM with $\theta_{c s}$ for $k_{v}=5 \%$ and $k_{z}=0.13 \tilde{p} u$

generated unwanted negative torque. This result in torque pulsation, speed reduction, increases in machine loss, derating of the machine etc. Additionally due to small value of negative sequence impedance, negative sequence voltage generates large negative sequence current and consequently increases of motor losses and reduction in motor life. It can be observed from Fig. 4, that the positive sequence voltage is exactly reflected in $k_{z}$ for any value of $k_{v}$, and hence it can be consider as the reflection of

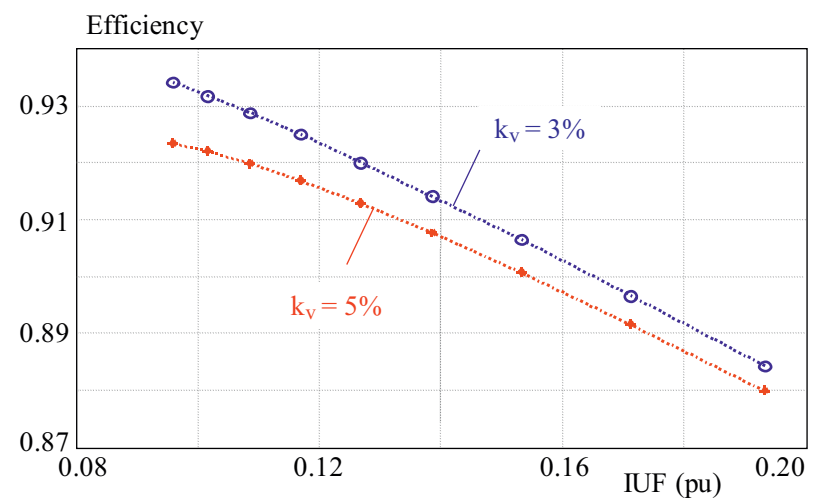

Fig. 5. The variation of the efficiency $(\mathrm{pu})$ with $k_{z}(\mathrm{pu})$

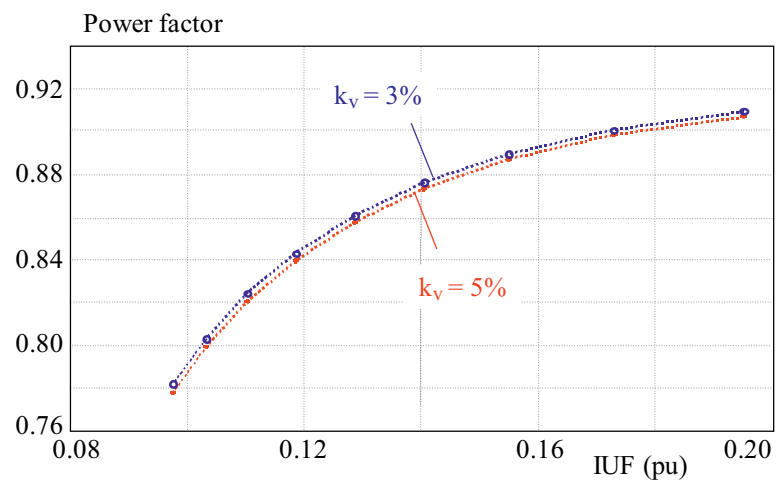

Fig. 7. The variation of power factor of IM with $k_{z}(\mathrm{pu})$

positive sequence voltage, which is deciding factor for the condition of unbalance [18].

In this section, $k_{z}, k_{\nu}$, and $\theta_{v}$ have been taken into consideration for the precise assessment of the performance of IM under different degree and manner of supply voltage unbalance. Further it has been asserted that for precise analysis under condition of unbalance these three factors should be taken into consideration.

\subsection{Effect of Supply Voltage Unbalance on Effi- ciency, Total loss and Power Factor of IM}

The variation of the efficiency of IM with $k_{z}$ for fixed value of $k_{v}$ is shown in Fig. 5 . It can be observed that the large degree of unbalance $\left(k_{v}\right)$ causes large reduction in machine efficiency. Further it can be observed that for the precise evaluation of the efficiency of the motor, $k_{v}$ alone is not sufficient, for $k_{v}=5 \%$, the range of efficiency lies between $88.99 \%$ and $92.34 \%$, the exact value of efficiency can be only evaluated after the knowing of value of $k_{z}$. At $k_{v}=0.05 \mathrm{pu}$, and $k_{z}=0.14 \mathrm{pu}$ the efficiency of the machine can be exactly calculated as $90 \%$. Thus $k_{v}$ and $k_{z}$ simultaneously should be applied for the precise evaluation of the efficiency. Additionally it is observed that in case of over-voltage the efficiency is larger than under-voltage. 


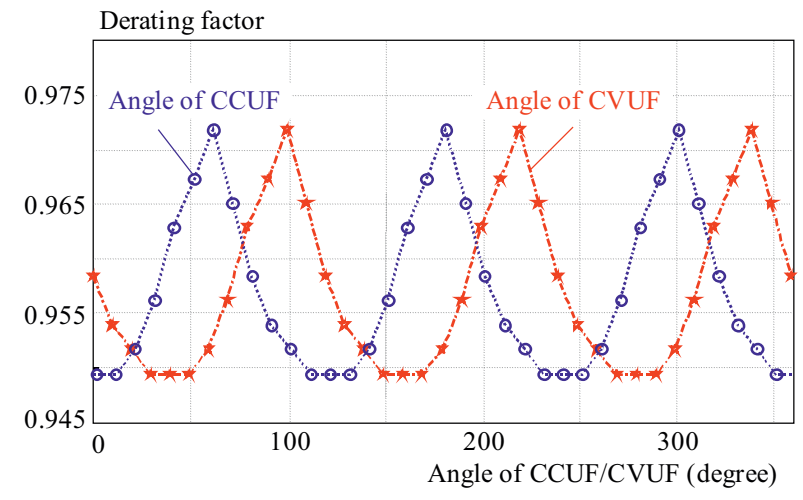

Fig. 9. The variation of derating factor with $\theta_{c s} / \theta_{\nu}$ for $k_{z}=$ $0.13 \mathrm{pu}$

The variation of total loss, which is summation of stator and rotor copper loss, of the IM under different condition and degree of unbalance with $k_{z}$ is shown in Fig. 6. It is observed that the total loss in under-voltage condition is more than the over-voltage condition. It can be observed further that for particular value of $k_{v}$ the total loss again depend on the unbalance condition which is exactly reflected in $k_{z}$. So for precise estimation of the performance of the machine it is again seen that $k_{v}$ alone is not sufficient but $k_{v}$ combined with $k_{z}$ gives accurate and unique result.

The variation of power factor with $k_{z}$ is shown in Fig. 7. It is observed that in case of over-voltage power factor is less in compared to under-voltage. It is further observed that for precise evaluation of voltage unbalance again we have to include $k_{z}$ with $k_{v}$.

Thus from Figs 6-8, it can be concluded that for accurate assessment of the performance of the machine $k_{z}$ should be included with $k_{v}$.

\subsection{Effect of Angle of Unbalance on Peak cooper loss, and Derating Factor of IM}

From (14)-(19), it can be observed that phase current of stator and rotor circuit depend on both $k_{c s}$ and $\theta_{c s}$. Peak value of three stator and rotor current for fixed value of $k_{c s}$ can be calculated from (14)-(19). For each value of $\theta_{c s}$, there are three stator and three rotor phase current. The maximum of these values at any $\theta_{c s}$ will be responsible for peak loss at that $\theta_{c s}$. Figure 8 shows the variation of peak value of stator, rotor, total copper loss with $\theta_{c s}$.

Due to superposition of the $V_{s 2}$ of the voltage over $V_{s 1}$, there is net reduction in output torque. If full load is still demanded, then the IM will be force to operate at higher slip, thus increasing the rotor losses and heat dissipation. The simplest protection to overcome this situation is suggested by NEMA standard, is to derate the motor so that it can able to tolerate the extra heating imposed by unbalance supply [7]. The factor by which output power is multiplied to derate the IM is termed as derating factor. Derating factor not only depend on the

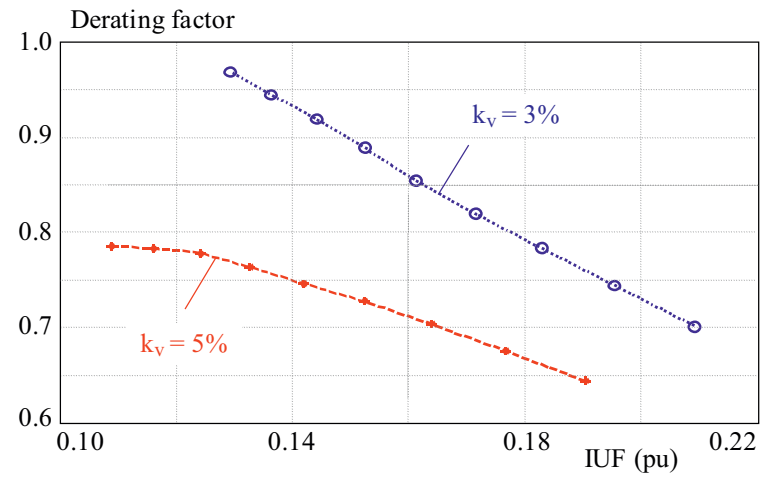

Fig. 10. The variation of derating factor (pu) with $k_{z}(\mathrm{pu})$ for fixed value of $k_{v}(\%)$

degree of unbalance but is also depend on the manner and angle of unbalance $[3,15]$. The derating factor of the machine is simply the ratio of output power at the slip corresponding to maximum stator current to rated power [15]. The variation of derating factor with $\theta_{c s} \& \theta_{v}$ for $k_{z}=0.13(\mathrm{pu})$ is shown in Fig. 9. It is clearly observed that derating curve with respect to $\theta_{v}$ and $\theta_{c s}$ is similar in nature, only there is slight shift. The shift is due the angle of $Z_{s 1}$ and $Z_{s 2}$, described in (13). It is further observed that, the $k_{z}$ is not sufficient to evaluate the value of derating factor, $\theta_{c s} / \theta_{\nu}$ must be included for the precise evaluation of the derating factor.

Figure 10 shows the variation of derating factor with $k_{z}$ (pu) for fixed value of $k_{v}$ and $\theta_{v}$. It can be observed that for large degree of unbalance the derating of the motor is more and further it can be seen that, under voltage require more derating than over-voltage. From Figs. 9 and 10, it can be concluded that for the precise calculation of the derating factor, $k_{v}$ is not sufficient, $k_{z}$ and $\theta_{c s}$ or $\theta_{v}$ must be included.

\section{CONCLUSION}

This paper presents the analysis of the steady state performance of IM under supply voltage unbalance condition. The need of insertion of IUF and along with CVUF for accurate assessment of the effect of supply voltage unbalance on the prevailing operation of motor has been asserted. It has been further asserted that to assess all the performance quantities precisely, knowledge of the manner and degree of unbalance is essential. Manner of unbalance is reflects in $k_{z}$ where as degree of unbalance reflects in the $k_{v}$ and hence inclusion of both unbalance factor for the precise evaluation of IM is suggested. The influence of the angle of unbalance on derating factor, peak losses and pattern of voltage has been also discussed. It is analytically shown that how the pattern of voltage changes with angle of unbalance. Additionally, the relation between $k_{z}$ with $V_{s 1}$ for fixed value of $k_{v}$ is also discussed. 


\section{REFERENCES}

[1] ANWARI, M.-HIENDRO, A. : New Unbalance Factor for EstInduction Motorating Performance of a Three-Phase INDUCTION MOTOR with Under- and Overvoltage Unbalance, IEEE Trans. Energy Convers. 25 No. 3 (Sep 2010), 619-625.

[2] SIDDIQUE, A.-YADAVA, G. S.-SINGH, B.: Effect of Voltage Unbalance on INDUCTION MOTORs, IEEE International Symposium on Electrical Insulation, Indianpolis, USA, Sep 2004, pp. 26-29.

[3] JOUANNE, A. V.-BANERJEE, B.: Assessment of Voltage Unbalance, IEEE Transaction on Power Delivery 16 No. 4 (Oct 2001), 782-790.

[4] GNACINSKI, P.: Windings Temperature and Loss of Life of an Induction Machine Under Voltage Unbalance Combined With Over- or Undervoltages, IEEE Transactions on Energy Conversion 23 No. 2 (June 2008), 363-371.

[5] LEE, C. Y.: Effects of Unbalanced Voltages on the Operation Performance of a Three-Phase INDUCTION MOTOR, IEEE Trans. Energy Convers. 14 No. 2 (June 1999), 202-208.

[6] WILliAMS, J. E.: Operation of 3-Phase INDUCTION MOTORs on Unbalanced Voltages, AIEE Trans. Power Apparat. Syst., pt. III 73 (Apr 1954), 125-133.

[7] PILLAY, P.-HOFTMAN, P.-MANYAGE, M. : Derating of INDUCTION MOTORs Operating with the Combination of Unbalanced Voltages and Over or Under Voltages, IEEE Trans. Energy Convers. 17 No. 4 (Dec 2002), 485-491.

[8] ZHELEZHENKO, I. V.-SAYENKO, Y. L.-GORPINICH, A. V.: Electrical Equipment Reliability Evaluation at the Voltage Distortion and Unbalance, Eighth International Conference Electrical Power Quality and Utilisation, Cracow, Poland, Sep, 21-23, 2005.

[9] de ABREU, J. P. G.-EMANUEL, A. E. : INDUCTION MOTOR Thermal Aging Caused by Voltage Distortion and Induction Motorbalance: Loss of Useful Life and its EstInduction Motorated Costs, IEEE Trans Ind Appl, 38 No. 1 (2002), 12-20.

[10] GAFFORD, B. N.-DUESTERHOEFT Jr., W. C.-MOSHER III, C. C.: Heating of INDUCTION MOTORs on Unbalanced Voltages, AIEE Trans. Power Apparat. Syst., pt. III-A 78 (June 1959), 282-297.

[11] KERSTING, W. H.-PHILIPS, W. H. : Phase Frame Analysis of the Effects of Voltage Unbalance on Induction Machine, IEEE Trans. Ind. Appl. 33 No. 2 (Mar/Apr 1997), 415-420.

[12] Motors and generators, ANSI7NEMA Standard MG1-1993.

[13] IEC Standard 61000-4-27: Testing and Measurement Techniques - Unbalance, Induction Motormunity Test, August 2000.

[14] SINGH, A. K.-SINGH, G. K.-MITRA, R. : Some Observations on Definitions of Voltage Unbalance, 39th North American Power Symposium, 2007, pp. 474-479.
[15] WANG, Y. J.: Analysis of Effects of Three-Phase Voltage Unbalance on INDUCTION MOTORs with Emphasis on the Angle of the Complex Voltage Unbalance Factor, IEEE Trans. Energy Convers. 16 No. 3 (Sep 2001), 270-275.

16] GNACINSKI, P.: Effect of Unbalance Voltage on Winding Temperature, Operation Life and Load Carrying Capacity of Induction Machine, Energy Conversion and Management 49 (2008), 761-770.

17] FAIZ, J.-EBRAHINDUCTIONMOTORPOUR, H.-PILLAY, P. : Influence of Unbalanced Voltageon the Steady-State Performance of a Three- Phase Squirrel-Cage INDUCTION MOTOR, IEEE Trans. Energy Convers. 19 No. 4 (Dec 2004), 657-662.

[18] LEE, C. Y.-CHEN, B. K.-LEE, W. J.-HSU, Y. F. : Effects of Various Unbalanced Voltages on the Operation Performance of an Induction Motor under the Same Voltage Unbalance Factor Condition, Electric Power System Research 47 No. 7 (Feb 1998), 153-163.

[19] REINERI, C. A.-GÓMEZ, J. C.-BALAGUER, E. B.-MORCOS, M. M. : ExperInduction Motorental Study of INDUCTION MOTOR Performance with Unbalanced Supply, Electric Power Components and Systems 34 No. 7 (Aug 2006), 817-829.

[20] KINNI, P. G.-BANSAL, R. C.-AITHAL, R. S. : A Novel Approach Toward Interpretation and Application of Voltage Unbalance Factor, IEEE Transaction on Industrial Electronics 54 No. 4 (Aug 2007).

Received 26 July 2012

Shashi Bhushan Singh received the B Tech degree in electrical engineering from UCER, Allahabad, India, in 2006, the $\mathrm{M}$ Tech degree in control and instrumentation from DCE, Delhi, India, in 2008, and is currently pursuing the $\mathrm{PhD}$ degree in electrical engineering from MNNIT Allahabad, India. His research interests are power quality issues in power system, and Electrical drive.

Asheesh Kumar Singh received the B Tech degree in electrical engineering from HBTI, Kanpur, India, in 1991, the $\mathrm{M}$ Tech degree in control systems from the REC, Kurukshetra, India, in 1994, and the PhD degree in electronics and computer engineering from the Indian Institute of Technology, Roorkee, India, in 2007. Since 1995, he has been on the academic staff of MNNIT, Allahabad, India, where he is currently Associate Professor with the Department of Electrical Engineering. His research interests are the application of soft computing techniques to power systems, distributed generation, power quality, and reliability. 